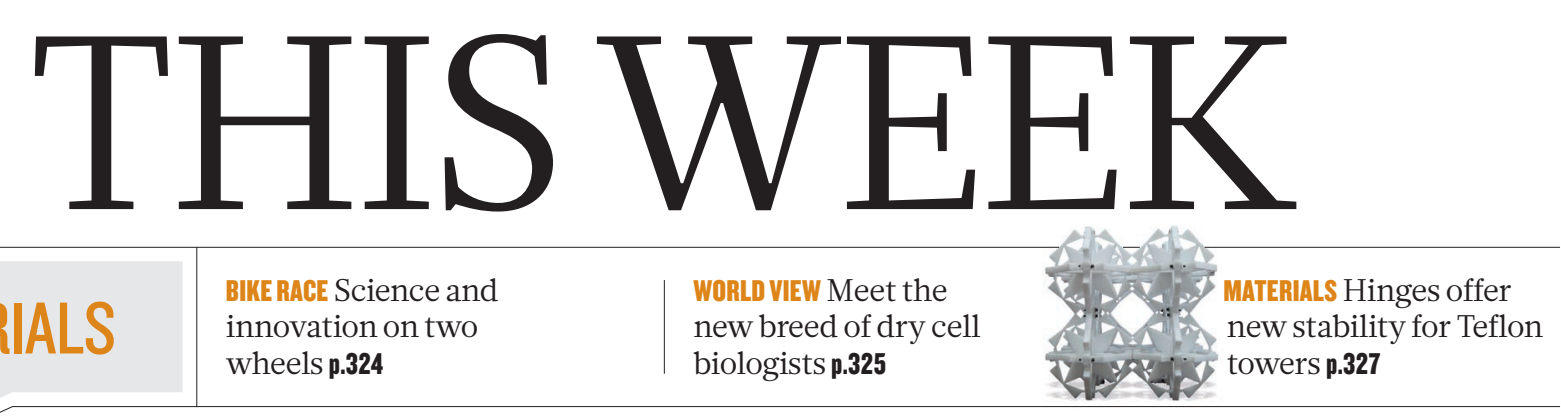

EDITORIALS innovation on two wheels p.324 new breed of dry cell biologists p.325

\title{
Forgotten foot soldiers of science
}

\author{
The story of CRISPR-Cas9 gene editing has tended to focus on a few key players. But, as with any \\ area of basic research, it takes a small army of talented researchers to make a discovery.
}

CT $t$ is amazing what you can accomplish if you do not care who gets the credit." Harry Truman supposedly said that, and as the US president who dropped the atomic bomb, he had more reason than most to be amazed.

Science is a collective effort, but human nature - including that of people who sit on grant committees and decide prizes - tends to select and reward individuals. Hence the popular parlour game among scientists: speculating on who will get the Nobel prize for impressive discoveries.

They don't come much more impressive than a molecular-biology technique that has swept through laboratories in the past few years, accelerating genetic research and tantalizing the public with its potential to change how genetic diseases are treated. As a result, the scientists who helped establish the technique - which rewrites DNA using a bacterial immune system called CRISPR-Cas9 - have received accolades and awards, and ample coverage in the media.

But the researchers who did much of the work - the graduate students and postdocs who carried out the experiments — are rarely mentioned. In this week's Nature, we take a look at a small sample of those researchers and how their experience with CRISPR has affected their careers (see page 342).

Our article is an attempt to grant these junior investigators a little of the limelight, but it also shows how difficult it is to do so: owing to space limitations, many young scientists who made important contributions to the field were left out of the article. (It is a decision that journalists face all the time, but it was made all the more painful in this case.)

The fairest approach would perhaps have been to replace the article with a simple two-page list, in fine print, of key researchers. Even then, there would be missing entries. The development of CRISPR gene editing is basic research at its finest: a handful of researchers initially noticed an oddity in bacterial genomes and decided to investigate, and this small squad swelled into a global army of scientists investigating every aspect of the system and how it can best be applied to treat diseases and engineer transgenic plants and animals. It is impossible to adequately assign credit in any one article or documentary - or on one awards podium. And that means postdoctoral researchers and graduate students are largely left unrecognized.

The focus on senior figures is rational. They are more likely to have spent many years pioneering a field, and principal investigators set the tone and direction of their laboratories.

There are also benefits to staying out of the public eye, particularly for young investigators. The barrage of interview and speaking requests takes time away from the focus needed to launch a laboratory. And becoming famous for a particular advance, particularly a technological one, can pigeonhole a young investigator at a time when they would rather spread their wings and visit new fields.

But there is also a price. Aside from the ego boost, awards
— particularly in the form of grants - bolster a career. Scientific fame that spreads outside one specific community has a greater chance of influencing review panels. This is particularly important for young investigators who are starting their careers in what suddenly becomes a highly competitive area. Senior investigators must ensure that they promote their best and brightest junior colleagues both inside and
"Postdoctoral researchers and graduate students are largely left unrecognized." outside their field.

The mentors featured in our article show that this can be done. They work hard to foster an atmosphere of independence and fearless exploration in their laboratories. They credit their graduate students and postdocs during talks, offer them opportunities to present at major conferences, and actively promote their careers - even long after their junior colleagues have moved on to other labs.

To achieve notoriety beyond scientific circles is a greater challenge, but still possible. Reporters often seek comment from celebrity scientists: the better known and more established, the better. In this case, reputation serves as a proxy for quality: given limited space, journalists seek to get the most credible comment that they can squeeze in. But good reporters sprinkle their articles with comments from younger investigators as well. Senior researchers can encourage this practice, and point journalists in the right direction.

Assigning scientific credit will never be entirely fair. But with consideration and support, wouldn't it be amazing if young investigators got a taste of the attention - and the career boost - they deserve?

\section{Virtual taxonomy}

\author{
People everywhere are catching Pokémon. Can \\ they also catch real new species?
}

$\mathrm{M}$ illions of people have spent the past week walking around. Ostensibly, they are playing the online game Pokémon Go and hunting for critters in an 'augmented reality' world. But as gamers wander with their smartphones - through parks and neighbourhoods, and onto the occasional high-speed railway line - they are spotting other wildlife, too.

Scientists and conservationists have been quick to capitalize on the rare potential to reach a portion of the public usually hunched over consoles in darkened rooms, and have been encouraging Pokémon hunters to snap and share online images of the real-life creatures they find. The question has even been asked: how long 